\title{
As cartas de Tell el-Amarna: classificação
}

\author{
The Tell el-Amarna letters: classification
}

\section{Las cartas de Tell el-Amarna: clasificación}

\author{
José Ademar Kaefer*
}

\begin{abstract}
RESUMO
As 382 cartas descobertas em Tell el-Amarna foram classificadas por Jorge Alexandre Knudtson e se mantêm assim até os dias atuais. Knudtson organizou as cartas em dois grandes grupos: aquelas enviadas pelos grandes reinos da época e aquelas enviadas pelos vassalos das cidades-Estado de Canaã. O segundo grupo pode ser dividido em outros dois subgrupos: o grupo norte, que segue o trajeto das cidades-Estado vassalas localizadas na região da costa marítima, de norte a sul; e as cidades-Estado centro e sul, que reúne as cidades localizadas em sua maioria no interior de Canaã, também seguindo uma sequência de norte a sul. É nesse segundo subgrupo que se encontram as cartas das cidades-Estado que tiveram influência direta na história do futuro Israel: Damasco, Hazor, Meguido, Siquém, Pella, Gath-Padalla, Guezer, Gat, Laquis e Jerusalém.

Palavras-chave: Cartas; Tell el-Amarna; Cidades-Estado; Canaã; Classificação.
\end{abstract}

\begin{abstract}
The 382 letters discovered at Tell el-Amarna were classified by Jorge Alexandre Knudtson and remain so until this day. Knudtson organized the letters into two great groups: those sent by the great kingdoms of that time and those sent by the vassals of the city-states of Canaan. The second group can be divided into two others subgroups: the northern group, which follows the route of the vassal city-states located more in the region of the sea coast, from north to south; and the central and southern city-states, which gathers the cities located mostly in the interior of Canaan, also following a north-south sequence. It is in this second subgroup where are the letters of the city-states that had a direct influence on the history of the future Israel: Damascus, Hazor, Megiddo, Shechem, Pella, Gath-Padalla, Gezer, Gath, Lachish and Jerusalem.
\end{abstract}

Keywords: Letters; Tell el-Amarna; Cities-state; Canaan; Classification.

\section{RESUMEN}

Las 382 cartas descubiertas en Tell el-Amarna fueron clasificadas por Jorge Alexandre Knudtson y se mantienen así hasta los días actuales. Knudtson organizó las cartas en dos grandes grupos: aquellas enviadas por los grandes reinos de la época y aquellas enviadas por los vasallos de las ciudades-Estado de Canaán. El segundo grupo puede ser dividido en otros dos subgrupos: el grupo norte, que sigue el trayecto de las ciudades-Estado vasallas localizadas en la región de la costa marítima, de norte a sur; y las ciudades-Estado centro y sur, que reúne las ciudades ubicadas en su mayoría en el interior de Canaán, también siguiendo una secuencia norte sur. Es en ese segundo subgrupo que se encuentran las cartas de las ciudades-Estado que tuvieron influencia directa en la historia del futuro Israel: Damasco, Hazor, Megido, Siquén, Pella, Gath-Padalla, Gezer, Gat, Laquis y Jerusalén.

Palabras clave: Cartas; Tell el-Amarna; Ciudades-Estado; Canaán; Clasificación.

* Docente titular de AT do Programa de Pós-Graduação em Ciências da Religião da Universidade Metodista de São Paulo (UMESP), coordenador do grupo de pesquisa "Arqueologia do Antigo Oriente Próximo” (http://portal.metodista.br/arqueologia). E-mail: jademarkaefer@gmail.com. 


\section{Introdução}

Quando descobertas no final do século XIX e início do século XX, as 382 cartas de Tell el-Amarna ${ }^{1}$ foram adquiridas pelos museus do Cairo, Berlim, Britânico, Louvre etc. O que não quer dizer que algumas não tenham perdidas ou destruídas no comércio clandestino ou ainda estejam em mãos privadas. Uma vez no museu, foi possível que as cartas fossem traduzidas com relativa rapidez (MYNAROVÁ, 2015, p. 40-41). Mesmo depois de publicadas, alguns originais se perderam, como a EA 7, que foi destruída quando Berlim foi bombardeada em 1945, ou a EA 135, que ficou deteriorada devido a um vazamento de água no museu de Ashmolean, em Oxford (RAINEY, 2015, p. 6-10).

Há cartas escritas pelo faraó destinadas a um colega, rei da Babilônia, Assíria etc., como as EA 1, 5, e 14, endereçadas ao rei da Babilônia. Mas, também há cartas escritas pelo faraó aos seus vassalos, como as EA 99, 162-163, 190, 367, 369, 370. Como foi que elas permaneceram em Amarna, uma vez que as cartas teriam de ser enviadas aos seus destinatários? A explicação possível é de que em alguns casos se fazia uma cópia, principalmente quando se tratava de um inventário (EA 13, 14, 22). Em outros casos parece que houve um erro na escrita, sendo necessário uma nova versão, a qual foi enviada, enquanto o tablete com o erro permaneceu. Às vezes também uma carta poderia ter sido escrita primeiro em egípcio e depois traduzida.

Uma das maiores referências, quando se trata da tradução e organização das cartas de El-Amarna é Jorgen Alexander Knudtson. ${ }^{2}$ Foi ele quem classificou e dividiu os tabletes como se mantém até os dias atuais. Knudtson buscou seguir no possível uma ordem cronológica e geográfica, classificando os tabletes em dois grandes grupos: 1) Aqueles enviados entre os grandes reinos da época; 2) Aqueles enviados pelos ou para os vassalos das cidades-Estado de Canaã, normalmente denominada de região Siro-palestinense.

\section{As cartas entre os grandes reinos}

Começando com os grandes poderes da época, possivelmente também organizados a partir do maior para o menor, na visão de Knudtson, as primeiras cartas tratam da relação entre o Egito e a Babilônia. Vejamos!

EA 1-14: Egito-Babilônia. Foram encontradas 14 correspondências entre o Egito e a Babilônia, com as quais Knudtson inicia sua numeração (EA 1 a

\footnotetext{
Sobre o contexto egípcio que produziram as cartas de Amarna em: Kaefer, J. A. "O

Linguista e assiriólogo norueguês (1854-1917), professor da Universidade de Oslo. Sua obra de referência: Die El-Amarna-Tafeln. Mit Einleitung und Erläuterungen, publicada em dois volumes em 1915 e reeditado em 1964.
} 
14). Evidentemente, a maioria das cartas é da Babilônia para o Egito. ${ }^{3}$ Os reis da Babilônia que enviam as cartas são Kadashman-Enlil e Burraburiash. Os que recebem são Amenhotep III e Amenhotep IV (Akenaton). Mas, há casos, como as EA 1 e 5, em que é o rei do Egito que envia para a Babilônia. Em geral, o tema principal são transações entre os dois reis e que normalmente envolvem mulheres princesas. Ou seja, o assunto constante é o casamento entre o rei de um reino com a princesa de outro. Junto com a comitiva que buscava a princesa ia sempre um grande dote em ouro, prata, bronze etc. ${ }^{4} \mathrm{O}$ casamento e o rico dote era uma forma de manter as boas relações entre os grandes poderes da época. O tratamento entre ambos os reis normalmente é amistoso, um trata o outro de irmão. Diferentemente da relação com os vassalos cananeus, onde estes sempre se apresentam como servos e tratam o faraó como deus.

Mas, não só de alianças e trocas de gentilezas tratam as cartas. $\mathrm{Na}$ EA $1^{5}$, por exemplo, Amenhotep III pede informações a Kadasman-Enlil a respeito de sua irmã e de sua filha enviadas à Babilônia, e das quais ele não sabe nem sequer se ainda estão vivas. $\mathrm{Na}$ EA 4, Kadashman-Enlil escreve a Amenotep III, com críticas, pois desconfia que a princesa enviada pelo faraó, e pela qual exigiu um alto dote, não seja de fato sua filha. Há também cartas particulares, como o caso da EA 12, enviada por uma princesa da Babilônia ao faraó egípcio, para que este não tenha maus pensamentos sobre ela em seu coração.

EA 15-16: Assíria-Egito. O mesmo tom seguem as duas cartas enviadas por Asur-Uballit, rei da Assíria, para Amenhotep IV. O tema central são os presentes enviados ao faraó e a troca de cortesias.

EA 17-30: Mitani-Egito. Mitani era uma extensa região ao norte da Assíria. O rei de Mitani, no período de Amarna, chamava-se Tushrata ${ }^{6}$. A maioria das cartas dele é enviada para Amenhotep III (17-26) e as demais para Amenhotep IV (COCHAV-RAINEY, 2015, p. 1393-1349). Também aqui os temas predominantes são os casamentos, o envio de presentes e a troca de gentilezas. A arte da diplomacia já era bastante útil e praticada na antiguidade (MYNAROVÁ, 2007).

Algumas correspondências chamam a atenção por sua particularidade. Eis alguns exemplos: as EA 27 e 29, por sua extensão, possivelmente as maiores de toda coleção; a EA 22, por sua longa lista de presentes, estes

3 O que não quer dizer que a Babilônia escrevesse mais, só não temos as cartas enviadas pelo faraó, a exceção de algumas, das quais foi feito uma cópia (veja comentário abaixo).

4 Como, por exemplo, a EA 13, que contém uma grande lista de presentes enviados pelo rei da Babilônia para uma princesa egípcia (COCHAV-RAINEY, 2015, p. 1341), o a EA 14, enviada por Amenhotep IV. Esta última, pela exagerada extensão da lista, seria para Goren (2005, p. 36) um inventário.

5 Que nunca foi enviada, possivelmente porque no final do tablete faltou espaço e algumas palavras ficaram faltando (COCHAV-RAINEY, 2015, p. 1323). Provavelmente outra cópia foi enviada.

${ }_{6}$ Por vezes escrito como Tuisherata. 
enviados por Tushratta a Amenhotep III, semelhante ao caso da EA 14, vista acima; a EA 30, por ser enviada para os reis de Canaã; a EA 18, muito fragmentada e por isso de difícil tradução, e por conter duas partes, que, talvez, não pertençam à mesma carta (MORAN, 1989, p. 43, n. 1).

EA 31-32: Egito-Arzaua. Duas cartas, a primeira enviada por Amenhotep III para Tarhundadu, rei de Arzaua, e a segunda, deste para aquele. Também aqui o tema que predomina é o do casamento entre os reis e as princesas.

EA 33-40: Alaxia-Egito. Todas as cartas são de Alaxia para o Egito. O governante não se identifica, apenas diz que é o rei de Alaxia. Talvez não houvesse necessidade, por ser bem conhecido. A EA 40 é do comissário de Alaxia para outro comissário do Egito. Também aqui os nomes de ambos não aparecem. O tema predominante das cartas é o informe do envio de bens: ouro, prata, cobre, cereais, cavalos e outros animais, muitas vezes via navio. Também aqui o rei de Alaxia se dirige ao faraó como irmão.

EA 41-44: Hati-Egito. Hati era um grande reino na região da Anatólia. $\mathrm{Na}$ época de Amarna, o rei de Hati era Supiluliuma, que enviou três cartas ao Egito, a quarta foi enviada por Zidan, príncipe de Hati. O tema que prevalece nas cartas é o da manutenção das relações amistosas entre os dois reinos. Chama a atenção o fato de Supiluliuma se apresentar como o sol (divindade), título que comumente o faraó se outorga.

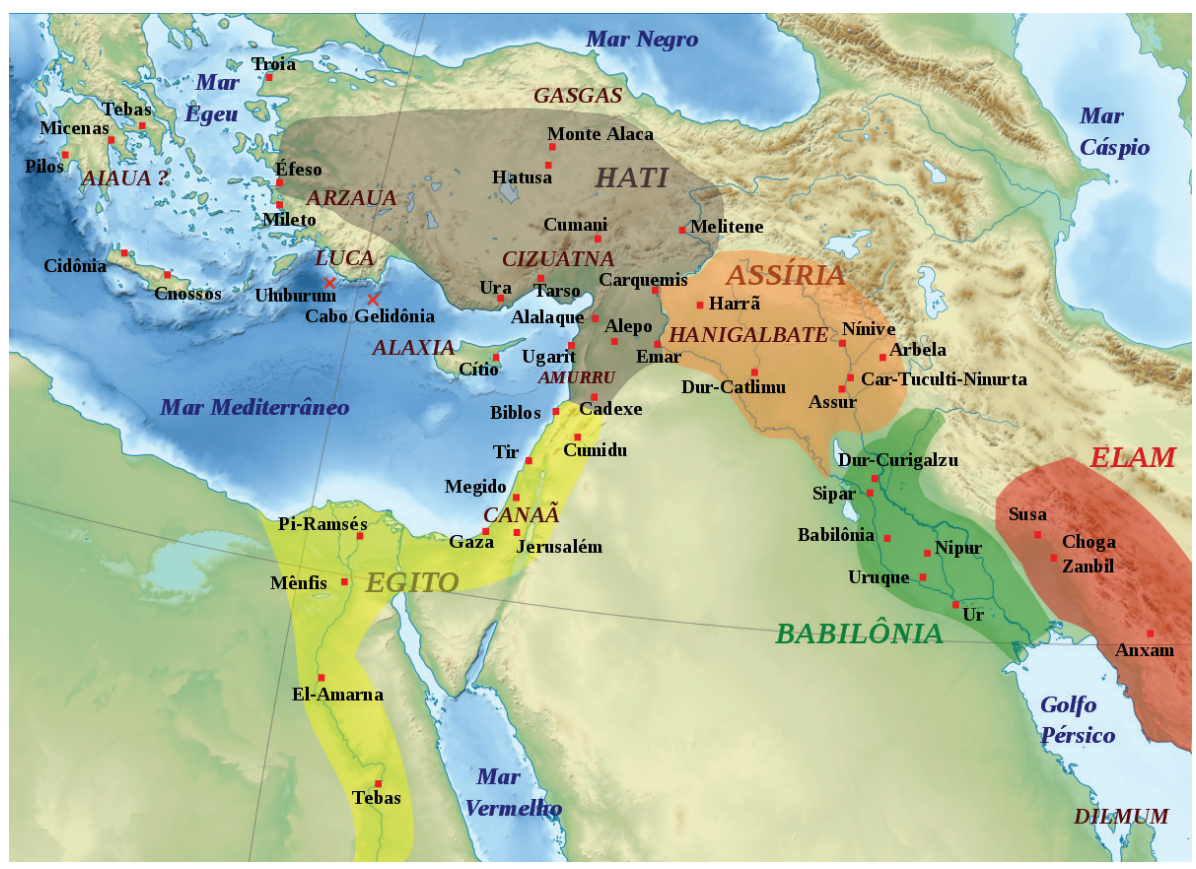

Reinos e cidades-Estado com os quais o Egito tinha relação comercial ou impunha seu domínio e mencionados nas cartas de Tell El-Amarna.

(https://www.lds.org/scriptures/bible-maps/map-9?lang=por). 


\section{As cartas entre as cidades-Estado vassalas e o Egito}

Ao segundo grupo correspondem as cartas entre os reis do Egito e seus vassalos da região de Canaã. Estas correspondências, em sua grande maioria dos vassalos para o Egito, Knudtson também buscou organizar seguindo uma ordem geográfica: começa no norte, passa pelo centro e termina no sul de Canaã. Este grupo, por sua vez, também pode ser dividido em dois: o grupo norte, que segue o trajeto das cidades-Estado vassalas localizadas mais na região da costa marítima, de norte a sul; e as cidades-Estado centro e sul, que reúne as cidades localizadas em sua maioria no interior de Canaã.

\subsection{As cidades-Estado do norte de Canaã}

EA 45-51: Ugarit-Egito. Nestas cartas aparecem dois reis de Ugarit: 'Amitamru I (EA 45) e Niamadu (EA 49). A EA 48, uma carta breve e bastante danificada, foi enviada por Heba, rainha de Ugarit, à rainha do Egito. A EA 50 por uma princesa de Ugarit à rainha do Egito. A EA 51 por Addu-Nirari, governante local de Nugasse, ao rei do Egito. O assunto nestas cartas muda completamente em relação às anteriores. Aqui prevalece a preocupação em mostrar a lealdade dos governantes ao faraó e o pleno cumprimento das exigências deste último.

EA 52-57: Qatna-Egito. Qatna estava localizada na região oeste da Síria, Tell el-Misrife (MYNAROVÁ, 2005, p. 445-459), e seu governante era Akizzi. Todas as seis cartas foram enviadas por ele. A dúvida fica por conta da EA 56, de cuja linha que traz a identidade do remetente está corrompida. Segundo COCHAV (2015, p. 1395-1401), todas foram enviadas para Amenhotep IV (Akenaton). Algumas cartas estão bastante danificadas (EA $52,54,57)$. Os temas que que prevalecem são acusações contra a atuação de cidades-Estado vizinhas (EA 56), particularmente contra Hati (EA 53), e as constantes declarações de fidelidade (EA 55).

As EA 58 e 59 são cartas isoladas. A primeira enviada por Tehu-Teshup, governante no norte de Canaã (?), ao Egito, e a segunda pelos cidadãos (MORAN, 1989, p. 130; filhos, RAINEY, 2015, p. 413) da cidade de Tunip, oeste da Síria, ao Egito.

EA 60-62; 156-171/173: Amurru-Egito. Amurru, localizada perto da costa marítima, na encosta oeste do Líbano (GOREN, 2005, p. 101), ao sul de Ugarit e a oeste de Qatna, era uma cidade-Estado rebelde, semelhante à Siquém de Lab’ayu. A rebelião foi deflagrada no tempo de Amenhotep III, para quem as primeiras cartas foram escritas. As EA 60-62 foram enviadas por 'Abdi-Ashirta, governante da cidade, e as EA 156-172/173 por 'Aziru, filho e sucessor de 'Abdi-Ashirta. A EA 169 foi enviada por DU-Teshup ou 
Bet-'ili, talvez filho de 'Aziru, a um oficial egípcio. A EA 170 foi enviada por Ba'luya e Beti-'li, talvez irmãos de 'Aziru, para 'Aziru, que se encontrava no Egito. As EA 163, 172 e 173 foram bastante danificadas (COCHAV-RAINEY, 2015, p. 1513), por isso é difícil saber de quem e para quem elas foram escritas, até se realmente são de Amurru.

Os pesquisadores têm se debatido quanto à localização de uma cidade chamada Tunip, que é mencionada várias vezes nas cartas de Aziru (EA 161, $165,166,167)$. Inclusive, uma (EA 159) foi enviada ao faraó pelo povo da cidade (GOREN, 2005 p. 101).

Nas entre linhas das cartas são constantes as acusações do faraó contra o comportamento de Aziru (EA 161-162; 166), que por sua vez se preocupa em manifestar reiteradamente sua lealdade ao faraó. Na EA 62 'Abdi-Ashirta fala de uma carta enviada pelo faraó onde ele é acusado de inimigo da terra do Egito.

EA 63-65: Gat-Egito. O remetente das cartas é 'Abdi-Ashtarti, mas o local, ou a capital do governante que envia, não é identificada. Assumimos sendo Gat (Tell es-Safi) a partir da análise petrográfica (GOREN, 2005, p. 284; NA'AMAN, 1979, p. 676). O tema predominante é pedido de envio de tropas regulares por causa das hostilidades contra ele, 'Abdi-Ashtari.

EA 66-140; 362: Biblos-Egito. De Biblos, também localizada na costa do Mediterrâneo, ao sul de Amurru, é que foram encontradas o maior número de cartas em Amarna. Boa parte foi enviada por Rib-Hada, governante de Biblos, diretamente aos reis do Egito. Outra parte foi enviada a oficiais egípcios. É o caso das EA 66 a 98, enviadas para Haya, vizir egípcio, para Anapa e para Amanappa, oficiais egípcios. A EA 99 foi envida pelo rei do Egito para o governante da cidade de 'Ammiya, vizinha de Biblos, e a EA 100 da cidade de 'Irqata ao rei do Egito. As EA 139-140 são de 'Ilu-Rapi, talvez sucessor de Rib-Hada, assim como a EA 362, enviada por Rib-Eddi, que também se apresenta como governante de Biblos.

Em geral as cartas são breves, mas há exceções, como a EA 129 (92 linhas), a EA 137 (103 linhas) e a EA 138 (138 linhas). Evidentemente que os temas tratados nesse alto número de correspondências são bem diversificados. Mas, em geral, há muitos assuntos em comum. Exemplos são: a submissão, típico das cartas enviadas por vassalos, praticamente presente em todas cartas enviadas de Biblos (MYNAROVÁ, 2005, p. 397-406); informes sobre a situação política de determinadas cidades; denúncias a respeito de ataques de cidades vizinhas; os pedidos de envio de tropas regulares; a hostilidade dos 'apirus; várias denúncias contra 'Abdi-Ashirta, governante da cidade vizinha e grande inimigo de Rib-Hadi; acusações contra Amurru, que estaria tomando as terras do faraó; denúncias contra os grandes reinos de Mitani e de Hati etc. 
EA 141-143: Beirute-Egito. Localizada também na costa mediterrânea, entre Biblos e Sidônia, Beirute tinha como governante vassalo no tempo de Amarna a 'Amunira, de quem foram encontradas três cartas.

EA 144-145: Sidônia-Egito. De Beirute, seguindo em direção ao sul, está Sidônia. Seu governante se chamava Zimreda, de quem foram encontradas duas cartas.

EA 146-155: Tiro-Egito. Continuando a trajetória na costa do Mediterrâneo rumo ao sul, a cidade-Estado seguinte é Tiro, uma das mais importantes da região. Seu governante se chamava Abimilki. Dele foram encontradas nove cartas.

EA 174 -292: cartas singulares. ${ }^{7}$ Grande número de correspondências encontradas em Tell el-Amarna são cartas singulares, ou seja, de remetentes que enviaram somente uma carta ou, então, cartas nas quais não é possível identificar seu remetente. É provável que a maioria destas cartas, que em geral são bastante breves, seja de governantes de pequenas cidades cananeias. As cartas, cujo remetente enviou mais de uma carta são: Ilu-Dayyani e seu sucessor, Mayarzana, governantes de Hasi (EA 175; 185 e 186); Shutarna, governante de Mushihuna (EA182; 183 e 184); Etakkama, governante de Qidsu (EA 189; 190) e Arzawuya, governante de Rogisi (EA 191; 192).

\section{2 As cidades-Estado cananeias centro e sul}

A partir da EA 193 começam as cartas enviadas pelas cidades-Estado centro e sul de Canaã. Aqui também, boa parte é de cidades singulares. Mencionaremos somente os governantes que enviaram um número plural de cartas. EA 194-197: enviadas por Biryawaza, governante de Damasco; EA 127; 228: enviadas por 'Abdi-shullim, governante de Hazor; EA 232235: enviadas por Surata e Satatna, governantes de Aco; EA 242-247; 365: enviadas por Biridiya, governante de Meguido; EA 249-250: enviadas por Ba'lu-UR.SAG, governante de Gath-Padalla/Rehov; EA 252-254: enviadas por Lab’ayu, governante de Siquém; EA 255-256: enviadas por Mut-Ba‘lu, governante de Pella; ${ }^{8}$ EA 257-260: enviadas por Ba'l-Meher, governante de Gath-Padalla; EA 264-266: enviadas por Tagi, governante de Ginti-Kirmil (GOREN, 2005, p. 256-258); EA 268-272; 378: enviadas por Milkilu, governante de Guezer; ${ }^{2}$ EA 273-274: enviadas pela Senhora dos leões (?); EA 275-277: enviadas por Ya'zib-Hada, de Canaã (COCHAV-RAINEY, 2015, p.

As EA 156-171/173, continuação da ordem, fazem parte das cartas enviadas de Amurru e já mencionadas acima.

8 A EA 256 foi enviada ao comissário Yanhamu.

9 A EA 369 foi enviada pelo faraó a Milkilu. A EA 272 foi enviada por Ba'lu-dani e a EA 378 por Yapa'u, talvez sucessores de Milkilu, ambas para o faraó. 
1584); ${ }^{10}$ EA 278-284;366: enviadas por Shuwardata, governante de Gath; EA 285-291: enviadas por 'Abdi-Heba, governante de Jerusalém. ${ }^{11}$

Como é possível perceber, neste bloco (EA 193-291) se encontram as cartas enviadas ou recebidas pelos governantes das cidades-Estado que têm maior relação com a história e a geografia do futuro Israel. Referimo-nos a Damasco, Hazor, Meguido, Siquém, Pella, Gath-Padalla, Guezer, Gat e Jerusalém.

A partir da EA 292 seguem novamente várias cartas singulares, uma por remetente, ou, então, sem identificação deste, também, provavelmente, de pequenas cidades-Estado de Canaã. Mencionaremos os governantes que enviaram mais de uma carta. EA 292-293; 295: enviadas por Ba'lu-dani ou Adda-danu, sem a identificação da cidade; EA 297-300: enviadas por Yapahu, governante de Guezer, sucessor de Milkilu? EA 301-306: enviadas por Shubandu, sem identificação da cidade; EA 314-316: enviadas por Pu-Ba'alu, governante de Yurza ; EA 317-318 enviadas por Dagantakala, sem identificação da cidade; EA 320-326; 370: enviadas por Yidia, governante de Asquelon; EA 328-332: enviada por Yabni-Ilu (328), por Zimredi (329) e por Shipti-Ba'lu (330-332), todos governantes de Laquis.

\section{Tabletes que não são cartas}

Há um grupo de 32 tabletes que não são considerados cartas ou inventários, por isso não abordados aqui. São textos com diversidades de gêneros: listas de divindades, mitos, épicos, silabários etc. É possível que alguns sejam exercícios de alunos da escola de escribas para o aprendizado da língua acádica (MORAN, 1987, p. xv; GOREN, 2004, p. 2). São eles: EA 340-361; 368; 372-377; 379-382.

\section{As cidades-Estado e os reinos em Canaã}

As cidades-Estado que se desenvolveram na era do Bronze na região de Canaã, principais protagonistas das cartas de Tell el-Amarna, podem ser divididas em dois tipos: as cidades-Estado da planície e as cidades-Estado das montanhas ou das terras altas (FINKELSTEIN; NA'AMAN, 2005, p. 172). As das planícies se caracterizavam pela força econômica. Tỉnham melhor produção agrícola e pecuária e maior atividade comercial, pois suas terras eram mais férteis e mais fáceis de cultivar. $^{12}$ Além disso, as principais

10 Todas são um pequeno bilhete, apenas confirmando de que o vassalo recebeu a carta do faraó e de que está enviando o pedido.

11 A EA 291 bastante deteriorada.

12 As cidades-Estado das planícies podem ser distinguidas entre as do interior e as da costa. As do interior eram predominantemente agrícolas. Enquanto que as da costa, por seu acesso ao mar, eram predominantemente comerciais. 
cidades-Estado da planície se desenvolviam junto às grandes rotas comerciais, o que possibilitava o controle do comércio que por ali passava, bem como maior facilidade para o escoamento da produção.

Por sua vez, as cidades-Estado das montanhas eram em geral mais pobres, ainda que o território controlado por elas fosse maior, em comparação aos das planícies. Não necessariamente a sua população, que em geral era menor. Durante o período das cartas de Amarna, tanto as cidades-Estado das planícies, quanto às das montanhas eram controladas pelo Egito (KAEFER, 2018a, p. 121-140). Contudo, o controle na montanha se fazia mais difícil que na planície, motivo pelo qual o foco das rebeliões acontecer normalmente nas montanhas. É o caso da revolta de Lab'ayu, que começou nas terras altas de Siquém e se espalhou para o sul, leste e oeste. O mesmo se dará com o início do Israel de Saul, alguns séculos depois (FINKELSTEIN; NA'AMAN, 2005, p. 172-193).

Os reinos em Canaã, que de certa forma substituem as cidades-Estado, somente começam a surgir mais tarde, quando não existe mais um poder imperial predominante. Isso acontece mais ou menos entre os anos $1125 \mathrm{e}$ 750, quando o domínio egípcio entra em declínio e a Assíria ainda não se impunha na região. Ou seja, um período de mais ou menos 350 a 400 anos. É nesse ínterim, por volta do século X, que se desenvolvem dois Estados fortes em Canaã: Israel Norte e Aram-Damasco. Ambos os poderes estarão em constante disputa territorial.

\section{Conclusão}

Quem organizou a sequência das cartas de Tell el-Amarna foi Jorge Alexander Knudtson. Ele dividiu as cartas em dois grandes grupos: aquelas enviadas pelos grandes reinos de então, como Babilônia, Assíria, Mitani etc., e aquelas enviadas pelos vassalos das cidades-Estados de Canaã.

$\mathrm{O}$ assunto que prevalece nas cartas entre os grandes reinos são as alianças feitas via casamento entre o rei e uma princesa, ato que sempre envolvia um rico dote. $\mathrm{O}$ tratamento entre ambos os reis é normalmente amistoso, onde um trata o outro de irmão. Fica evidente o papel da alta diplomacia na manutenção da paz entre os reinos.

Nas cartas enviadas pelos vassalos, o tratamento é totalmente diferente. Nestas, a maior preocupação dos governantes é mostrar sua submissão e lealdade ao faraó. Os assuntos que prevalecem são informes sobre a situação política da cidade-Estado, pedidos de envio de tropas regulares, acusações contra o ataque de cidades vizinhas, hostilidade dos 'apirus etc. O destaque deste grupo fica por conta do alto número de cartas enviadas por Biblos, 
bem como de cartas singulares ou sem a identificação da cidade e do governante remetentes.

As cartas de maior interesse para a pesquisa bíblica sãos as enviadas ou recebidas pelos vassalos das cidades-Estado localizadas na região centro e sul de Canaã. Particularmente as cidades de Damasco, Hazor, Meguido, Siquém, Pella, Gath-Padalla, Guezer, Gat e Jerusalém. Nelas é possível perceber uma grande revolta que se instaurou contra o Egito na idade do Bronze Tardio, liderada por Laba'yu, governante de Siquém (KAEFER, 2018b, p. 93-109). As revoltas futuras, como a de Saul e dos omridas, seguirão a mesma rota geográfica (FINKELSTEIN, 2006, p. 171-193; KAEFER, 2016, p. 402-426).

\section{Referências}

COCHAV-RAINEY, Zipora (ed.). The El-Amarna Correspondence: a new edition of the Cuneiform Letters from de Site of El-Amarna based on Collations of all Extant Tablets. Vol. II. Leiden-Boston: Brill, 2015.

FINKELSTEIN, I. The Last Labayu: king Saul and the expansion of the first north israelite territorial entity. In: AMIT, Y.; BEN ZVI, E.; FINKELSTEIN, I; LIPSCHITS, O. (Orgs.). Essays of Ancient Israel in its Near Eastern Context. A tribute to Nadav Na'aman. Wininona Lake: Eisenbraus, 2006, p. 171-193.

FINKELSTEIN, I.; NA'AMAN, N. Shechem of the Amarna Period and the Rise of the Northern Kingdom of Israel. Israel Exploration Journal, Tel Aviv, vol. 55, p. 172-193, 2005.

GOREN, Y.; FINKELSTEIN, I.; NA'AMAN, N. Inscribed in clay: provenance study of the Amarna Letters and other ancient Near Eastern texts. Tel Aviv: Tel Aviv University, 2004.

KAEFER, J. A. À procura de Saul! Uma análise de Primeiro Samuel 9-(12)14. Horizonte, Belo Horizonte, n. 42, p. 402-426, 2016.

KAEFER, José Ademar. As cartas de Tell El-Amarna e o contexto egípcio nos reinados de Amenhotep III e Amenhotep IV (Akenaton). Estudos de Religião, São Bernardo do Campo, v. 32, n. 1, p. 121-140, 2018a.

KAEFER, José Ademar. A resistência política pró-Egito em Canaã no período de Amarna. Perspectiva Teológica, Belo Horizonte, vol. 50, n. 1, p. 93-109, 2018 b.

KNUDTSON, J. A. Die El-Amarna-Tafeln. Mit Einleitung und Erläuterungen. Erster Teil Die Texte. Zweiter Teil Anmerkungen und Register bearbeitet von Otto Weber und Erich Ebeling. Leipzig/Aalen: 1915/1964.

MORAN, William L. The Amarna letters. Baltimore/London: The Johns Hopkins University Press, 1989/1992.

MYNAROVÁ, J. A Comment on the Opening Passages of the Amarna Letters - Its Structure and Its Addres. Archiv orientální. Quaterly Journal of African and Asian Studies, vol. 73, p. 397-406, 2005.

MYNAROVÁ, Jana. Akizzi of Qatna: a case of a diplomatic faux pas?. Ugarit-Forschungen, Münster, n. 37, p. 445-459, 2005. 
MYNAROVÁ, J. Language of Amarna: language of diplomacy. Perspectives on the Amarna Letters. Praga: University in Prague, 2007.

MYNAROVÁ, J. Discovery, research and excavation of the Amarna Tablets: the formative stage. In: RAINEY, A. F. The El-Amarna Correspondence. A new edition of the Cuneiform Letters from de site of El-Amarna based on collations of all extant tablets. Leiden-Boston: Brill, 2015, p. 37-46.

NA'AMAN, N. The origin and historical background of several Amarna Letters. UgaritForschungen, vol. 11, p. 673-684, 1979.

RAINEY, A. F. The El-Amarna Correspondence. A new edition of the cuneiform letters from de site of El-Amarna based on collations of all extant tablets. Leiden-Boston: Brill, 2015. 